\title{
Characterization of amorphous hydrogenated carbon films deposited by MFPUMST at different ratios of mixed gases
}

\author{
HAIYANG DAI, CHANGYONG ZHAN ${ }^{\dagger}$, HUI JIANG ${ }^{\dagger}$ and NINGKANG HUANG ${ }^{\dagger}, *$ \\ Department of Technology and Physics, Zhengzhou University of Light Industry, Zhengzhou 450002, P. R. China \\ $\dagger$ Key Laboratory of Radiation and Technology of Education Ministry of China, Institute of Nuclear Science and \\ Technology, Sichuan University, Chengdu 610064, P. R. China
}

MS received 14 March 2011; revised 29 October 2011

\begin{abstract}
Amorphous hydrogenated carbon films ( $a-\mathrm{C}: \mathrm{H})$ on $p$-type (100) silicon wafers were prepared with a middle frequency pulsed unbalanced magnetron sputtering technique (MFPUMST) at different ratios of methaneargon gases. The band characteristics, mechanical properties as well as refractive index were measured by Raman spectra, X-ray photoelectron spectroscopy (XPS), nano-indentation tests and spectroscopic ellipsometry. It is found that the $s p^{3}$ fraction increases with increasing Ar concentration in the range of 17-50\%, and then decreases when Ar concentration exceeds $50 \%$. The nano-indentation tests reveal that nano-hardness and elastic modulus of the films increase with increasing Ar concentration in the range of 17-50\%, while decreases with increasing Ar concentration from $50 \%$ to $86 \%$. The variations in the nano-hardness and the elastic modulus could be interpreted due to different $s p^{3}$ fractions in the prepared $a-\mathrm{C}: \mathrm{H}$ films. The variation of refractive index with wavelength have the same tendency for the $a-\mathrm{C}: \mathrm{H}$ films prepared at different Ar concentrations, they decrease with increasing wavelength from 600 to $1700 \mathrm{~nm}$. For certain wavelengths within $600-1700 \mathrm{~nm}$, refractive index has the highest value at the Ar concentration of $50 \%$, and it is smaller at the Ar concentration of $86 \%$ than at $17 \%$. The results given above indicate that ratio of mixed gases has a strong influence on bonding configuration and properties of $a-\mathrm{C}: \mathrm{H}$ films during deposition. The related mechanism is discussed in this paper.
\end{abstract}

Keywords. Amorphous hydrogenated carbon; middle frequency pulsed unbalanced magnetron sputtering technique; $s p^{3}$ content; mechanical properties; refractive index.

\section{Introduction}

Amorphous hydrogenated carbon $(a-\mathrm{C}: \mathrm{H})$ films are metastable and in amorphous phase of carbon having $s p^{3}$ and $s p^{2}$ bonds with various amounts of hydrogen. $a-\mathrm{C}: \mathrm{H}$ films have been investigated extensively due to their attractive properties including high hardness, low-friction coefficient, good wear-resistance, high optical transparency, high electrical resistivity, chemical inertness and biocompatibility (Clin et al 1999; Dai et al 2007; Kumari et al 2009). Therefore, they are widely used as hard transparent optical coatings, wear-resistant films in precision-machining, abrasion-resistant films in microelectronic-mechanical systems, low- $k$ dielectric films in integrated circuits and biocompatible coatings (Clin et al 1999; Kumari et al 2009).

$a$-C:H films have been synthesized by a variety of methods for different applications such as plasma enhanced chemical vapour deposition, dielectric barrier discharge deposition, ion beam deposition, arc ion plating and magnetron sputtering etc (Robertson 2002; Zou et al 2004; Dey et al 2008). It is known that $a-\mathrm{C}: \mathrm{H}$ is mainly composed of $s p^{3}$ and $s p^{2}$ and the properties of $a-\mathrm{C}: \mathrm{H}$ films are strongly affected by

\footnotetext{
*Author for correspondence (huang-072@163.com)
}

the ratio of $s p^{3} / s p^{2}$. It is found that the ratio of $s p^{3} / s p^{2}$ is dependent on different deposition methods and their preparation parameters. For a certain preparation method, the ratio of $s p^{3} / s p^{2}$ in films can be adjusted by adjusting one or two even three deposition parameters; consequently, film properties can also be controlled. Therefore, it is very important to look for some preparation parameters which can mainly control the ratio of $s p^{3} / s p^{2}$ in the prepared $a$-C:H films. Much works have been performed on the relationship between film properties and deposition parameters (Robertson 2002; Zou et al 2004; Myung et al 2005; Dey et al 2008).

There are a lot of magnetron sputtering methods widely used for industrial applications due to their good reproducibility and controllability with large areas, high deposition rates and low deposition temperature. In our work, middle frequency pulsed unbalanced magnetron sputtering technique (MFPUMST) is used to deposit $a$-C:H films, such a method can effectively improve the adhesion of the coatings to substrate without adding substrate bias owing to the enhancement of the plasma density near the substrate (Dai et al 2009), and can significantly reduce arcs during film preparation due to pulsing the magnetron discharge, hence, improve quality of the deposited films (Huang et al 2006; Dai et al 2009). 
$a-\mathrm{C}: \mathrm{H}$ film has a wide bandgap and its refractive index is variable by controlling the preparation parameters. Therefore, $a-\mathrm{C}: \mathrm{H}$ film can be used as an antireflective protective surface layer matching infrared coatings for infrared windows. Such a $a-\mathrm{C}: \mathrm{H}$ film should have a controlled refractive index as well as super mechanical properties. In this paper, one of deposition parameters, ratio of mixed gases, was changed to study its effects on bonding and properties of films deposited by MFPUMST.

\section{Experimental}

A middle frequency pulsed unbalanced magnetron sputtering technique (MFPUMST) was used to deposit $a-\mathrm{C}: \mathrm{H}$ films on $\mathrm{Si}(100)$ wafers with $40 \mathrm{kHz}$ at $200 \mathrm{~mA}$ in a $80 \%$ duty factor. The silicon wafers as substrates were ultrasonically cleaned in acetone and ethanol for about $10 \mathrm{~min}$, then rinsed in deionized water, and finally dried before installing in the vacuum chamber. The surface of the substrate was then bombarded by Ar plasma with $700 \mathrm{~V}$ bias voltage for more than $10 \mathrm{~min}$ to remove the surface contaminations prior to film deposition on it. Both $\mathrm{Ar}$ and $\mathrm{CH}_{4}$ are with a purity of $99.99 \%$, and the purity of graphite target is also $99.99 \%$. A base pressure of $5 \times 10^{-4} \mathrm{~Pa}$ in chamber was changed to $4 \times 10^{-1} \mathrm{~Pa}$ due to putting Ar gas and then $\mathrm{CH}_{4}$ gas into discharge chamber during film deposition. Samples were prepared at room temperature with 0 bias for $3 \mathrm{~h}$, and the Ar concentration $\left(\mathrm{Ar} / \mathrm{Ar}+\mathrm{CH}_{4}\right)$ in $\mathrm{CH}_{4}-\mathrm{Ar}$ mixture gases selected was $17 \%$, $33 \%, 50 \%, 67 \%$ and $86 \%$, respectively.

A RM2000 instrument by Renishaw, UK, with a $514.5 \mathrm{~nm}$ $\mathrm{Ar}^{+}$laser source was used for Raman spectral analysis. Xray photoelectron spectroscopy (XPS) studies were carried out on the deposited films using a PHI Quantera SXM system with monochromatic Al K $\alpha$ radiation $(1486.6 \mathrm{eV})$. A fully calibrated MTS Nano Indenter XP was used for nanohardness and elastic modulus measurement of the films, all data of hardness and elastic modulus in the paper are obtained as an average value with 3 tested points. The refraction index of the films was determined by a M-2000DI spectroscopic ellipsometer (SE) in the wavelength range from 600 to $1700 \mathrm{~nm}$.

\section{Results and discussion}

Raman spectroscopy is widely used to characterize structural quality of diamond, graphites, DLCs and carbon nanotubes, because of its sensitivity to changes in translation symmetry (Robertson 2002; Buijnsters et al 2006). The Raman spectra of $a-\mathrm{C}: \mathrm{H}$ films consist of two peaks, the $G$ peak around $1560 \mathrm{~cm}^{-1}$ and the $D$ peak around $1360 \mathrm{~cm}^{-1}$, for visible excitation (Robertson 2002; Buijnsters et al 2006; Dai et al 2007). The Raman spectra were deconvoluted with Gaussian curve fitting and the fitted parameters were used as the Raman parameters, including the peak position, bandwidth and spectra intensity. In fact, both $D$ and $G$ peaks are attributed to $s p^{2}$ bonding in the visible Raman spectra, the

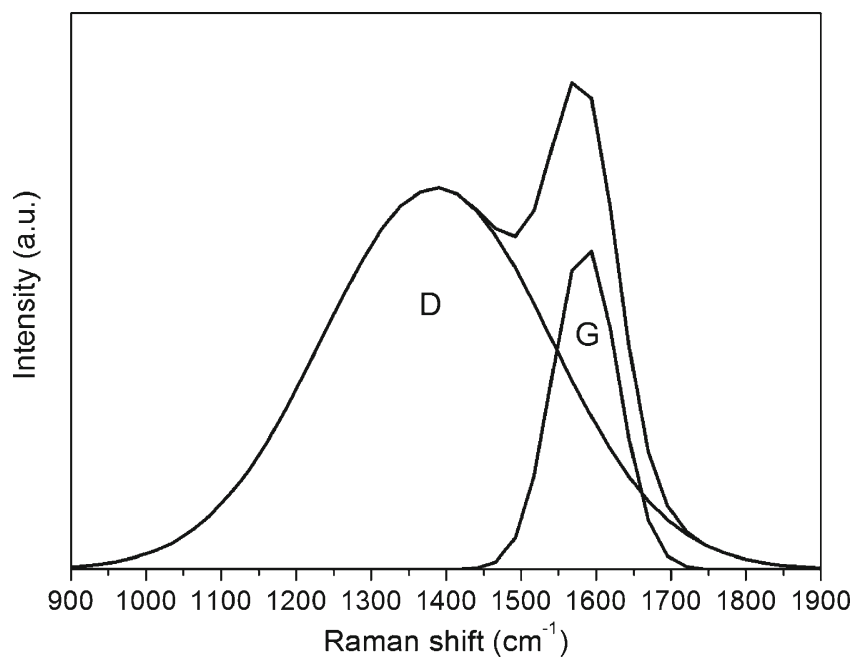

Figure 1. Raman spectrum of $a-\mathrm{C}: \mathrm{H}$ film deposited at $17 \% \mathrm{Ar}$ concentration.

Table 1. Bandwidth of $G$ peak of $a-\mathrm{C}: \mathrm{H}$ films deposited at different Ar concentrations.

\begin{tabular}{lccccc}
\hline Ar concentration $(\%)$ & 17 & 33 & 50 & 67 & 86 \\
\hline Bandwidth of $G$ peak $\left(\mathrm{cm}^{-1}\right)$ & 86.8 & 89.3 & 92.6 & 88.2 & 79.7 \\
\hline
\end{tabular}

$D$ peak is due to a breathing mode of those $s p^{2}$ sites only in rings, not in chains. The $G$ peak is due to a stretching vibration of any pair of $s p^{2}$ sites, either in $\mathrm{C}=\mathrm{C}$ chains or in aromatic rings. Thus, $G$ peak does not only mean 'graphite' (Robertson 2002; Buijnsters et al 2006; Dai et al 2007). A new criteria for judging $s p^{3}$ fraction in the $a-\mathrm{C}: \mathrm{H}$ films have been developed by us, in which the bandwidth of $G$ peak can be used to measure $s p^{3}$ content, a wider bandwidth of $G$ peak indicates a higher $s p^{3}$ fraction in the $a-\mathrm{C}: \mathrm{H}$ films (Dai et al 2007).

Figure 1 shows Raman spectrum of $a$-C:H film prepared at a Ar concentration of $17 \%$. The Raman spectrum decomposed by Gaussian fitting can be obtained as two peaks denoted as $G$ and $D$ at 1584 and $1388 \mathrm{~cm}^{-1}$, respectively. Similar spectra can be obtained for the $a-\mathrm{C}: \mathrm{H}$ films deposited at other different Ar concentrations. The bandwidth of $G$ peak with different Ar concentrations is shown in table 1. The bandwidth of $G$ peak is $86.8 \mathrm{~cm}^{-1}$ when the Ar concentration is $17 \%$, it is $89.3 \mathrm{~cm}^{-1}$ when the Ar concentration is $33 \%$, it increases to $92.6 \mathrm{~cm}^{-1}$ when the Ar concentration is $50 \%$. Then it decreases to $88.2 \mathrm{~cm}^{-1}$ when the Ar concentration is $67 \%$, and it becomes $79.7 \mathrm{~cm}^{-1}$ when the Ar concentration is $86 \%$. These data seem to indicate that the bandwidth of $G$ peak monotonously increases when the Ar concentration was in the range of $17-50 \%$, and then monotonously decreases when the Ar concentration was in the range of 50-86\%. It seems that the $s p^{3}$ fraction increases when the Ar concentration was in the range of $17-50 \%$, and then decreases when the Ar concentration was in the range of $50-86 \%$. Therefore, 


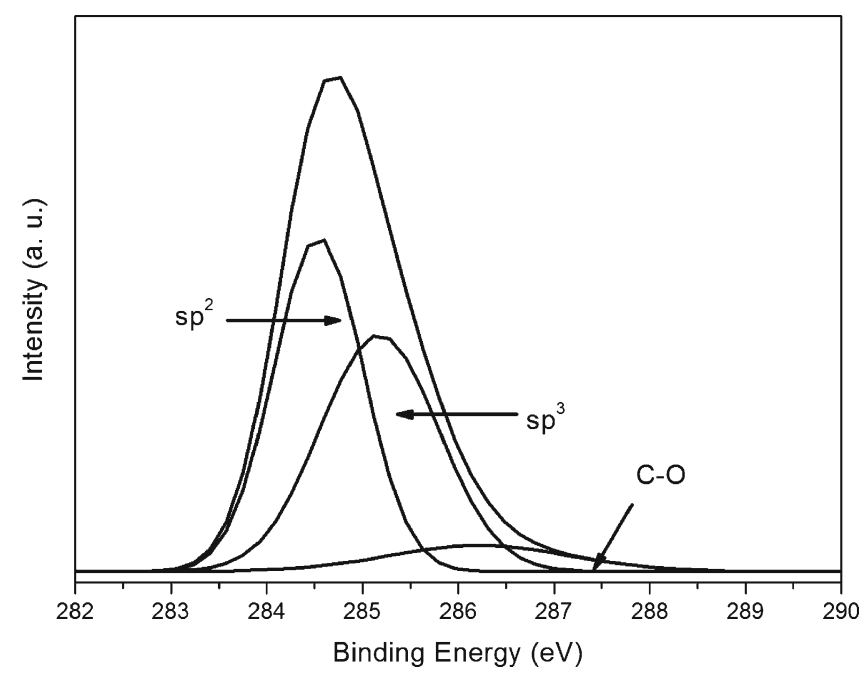

Figure 2. Deconvolution of XPS $\mathrm{C}_{1 s}$ peaks of $a-\mathrm{C}: \mathrm{H}$ film deposited at $17 \%$ Ar concentration.

Table 2. $s p^{3} / s p^{2}$ ratio based on XPS measurements for $a-\mathrm{C}: \mathrm{H}$ films deposited at different Ar concentrations.

\begin{tabular}{lccccc}
\hline Ar concentration (\%) & 17 & 33 & 50 & 67 & 86 \\
\hline$s p^{3} / s p^{2}$ & 1.28 & 1.42 & 1.52 & 1.37 & 1.16 \\
\hline
\end{tabular}

a highest $s p^{3}$ content in the $a$-C:H films can be obtained at the Ar concentration around 50\% during film deposition.

Raman spectroscopy is relatively unreliable in quantitative analysis of DLC films. To get quantitative results of film composition $\left(s p^{3}: s p^{2}\right)$, XPS analysis was employed. The deconvolution of XPS $\mathrm{C}_{1 s}$ peaks of the $a-\mathrm{C}: \mathrm{H}$ film prepared at a Ar concentration of $17 \%$ is shown in figure 2. One component at $284.5 \mathrm{eV}$ corresponds to $s p^{2}$ bond configuration, the second at $285.1 \mathrm{eV}$ is due to $s p^{3}$ bond one, and the third peak at $286.3 \mathrm{eV}$ is attributed to $\mathrm{C}-\mathrm{O}$ contamination due to the exposure of samples in air (Wang et al 2007). The ratio of $s p^{3} / s p^{2}$ was determined by the ratio of the corresponding peak area (Wang et al 2007). Table 2 shows $s p^{3} / s p^{2}$ ratio based on XPS measurements at different Ar concentrations. The $s p^{3} / s p^{2}$ ratio is 1.28 when the Ar concentration is $17 \%$, it is 1.42 at Ar concentration of $33 \%$, it increases to 1.52 at Ar concentration of $50 \%$. Then it decreases to 1.37 when Ar concentration is $67 \%$, and it becomes 1.16 at the $\mathrm{Ar}$ concentration of $86 \%$. This means that the $s p^{3}$ fraction increases with increasing Ar concentration from 17\% to $50 \%$, then decreases with increasing Ar concentration from $50 \%$ to $86 \%$. XPS result is consistent with that based on Raman measurement.

One of the most accepted models used to explain the deposition process of $a-\mathrm{C}: \mathrm{H}$ films is the sub-plantation model which is suitable for carbon species with energy approximately from 10 to $1000 \mathrm{eV}$ (Lifshitz 1996; Robertson 2002). When the energy of an impinging species $\left(E_{\mathrm{im}}\right)$ is lower than the energy of penetration threshold $\left(E_{\mathrm{p}}\right)$, i.e. $E_{\mathrm{im}}<E_{\mathrm{p}}$, such a species releases its energy via thermal spikes and just stick to the surface layers, and remain in their lowest energy state which is $s p^{2}$ (Lifshitz 1996; Robertson 2002). When $E_{\mathrm{im}}>E_{\mathrm{p}}$, the carbonaceous species start penetrating the subsurface layers and get accommodated in the interstitial sites leading to an increase of the local density. The local bonding will then reform around that atom according to this new density, i.e. the local bonding tends to change to $s p^{3}$ (Robertson 2002). However, when the energy of an impinging species are so high, they will cause increase of substrate temperature. In such a situation, carbonaceous species trapped in sub-surface area have to migrate to the top surface leading to the decrease in film density. Therefore, structure of film then changes from diamond-like carbon to graphite structure (Peng et al 2001; Robertson 2002; Chowdhury et al 2004). It has been found that the kinetic energy of argon ions is usually higher than hydrocarbon ions in the plasma of methane-argon gas (Liu et al 2006); the number of argon ions increases with increasing Ar concentration, the collision probability between $\mathrm{Ar}$ ions and hydrocarbon ions increases leading to more energy translated from argon ions to hydrocarbon ions, in other words, the kinetic energy of hydrocarbon ions increases with increasing Ar concentration (Chowdhury et al 2004). Based on the sub-plantation model, the fraction of carbonaceous species trapped in sub-surface area is increased with increasing Ar concentration from $17 \%$ to $50 \%$, which causes increase in local density of the film; hence, fraction of $s p^{3}$ component is increased. But, when $\mathrm{Ar}$ concentration further increases, energy of carbonaceous ions is also increased causing increase of substrate temperature leading to carbonaceous species trapped in sub-surface area to migrate to the surface, and local density of the film is then decreased causing a decrease in $s p^{3}$ fraction. And this is also why $s p^{3}$ fraction of the $a-\mathrm{C}: \mathrm{H}$ film prepared at the Ar concentration of $86 \%$ is lower than that at $17 \%$.

Nanoindentation technique is now widely used in evaluating the mechanical properties of thin and ultra-thin films.

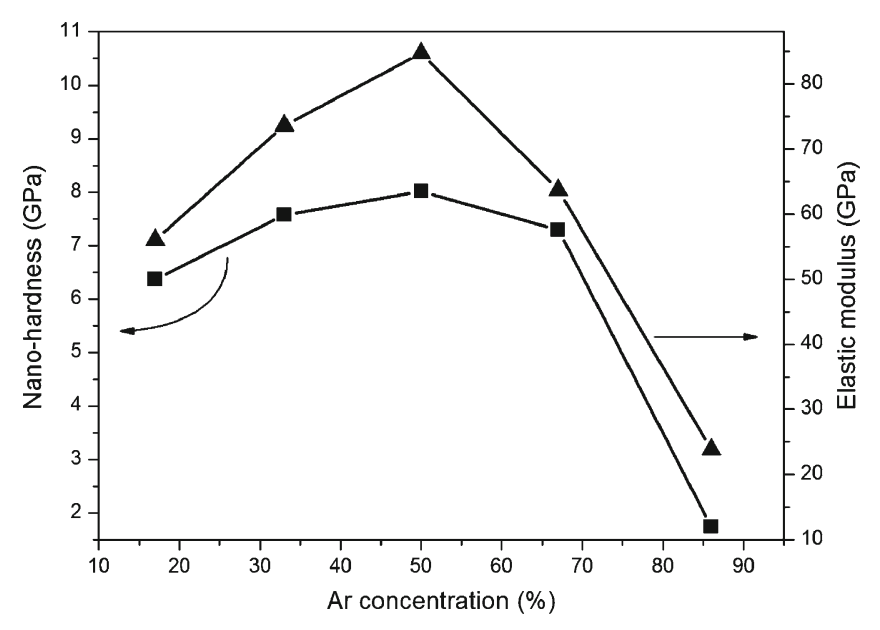

Figure 3. Nano-hardness and elastic modulus of $a-\mathrm{C}: \mathrm{H}$ films as a function of $\mathrm{Ar}$ concentration. 
Figure 3 shows nano-hardness and elastic modulus of $a-\mathrm{C}: \mathrm{H}$ films as a function of $\mathrm{Ar}$ concentration. The nanohardness increases from $6.636 \mathrm{GPa}$ at $17 \%$ Ar concentration to $8.014 \mathrm{GPa}$ at $50 \% \mathrm{Ar}$ concentration, however, further increase in Ar content results in a rapid decrease of nano-hardness. The elastic modulus also increases from $56.028 \mathrm{GPa}$ at $17 \%$ Ar concentration to $84.678 \mathrm{GPa}$ at $50 \%$ Ar concentration and then decreases to $23.835 \mathrm{GPa}$ at $86 \%$ Ar concentration. The nano-hardness and elastic modulus of the $a-\mathrm{C}: \mathrm{H}$ films have the same tendency, and the highest values of nano-hardness and elastic modulus were obtained from the $a-\mathrm{C}: \mathrm{H}$ film deposited at $50 \% \mathrm{Ar}$ concentration. Obviously, hardness and elastic modulus are dependent on the $s p^{3}$ fraction in the $a-\mathrm{C}: \mathrm{H}$ films, in other words, the higher $s p^{3}$ fraction in the $a-\mathrm{C}: \mathrm{H}$ films, the higher the hardness and elastic modulus (Robertson 2002; Dai et al 2007). According to the measured Raman and XPS results, highest $s p^{3}$ fraction can be obtained for the $a-\mathrm{C}: \mathrm{H}$ films deposited at a Ar concentration of $50 \%$. Also, highest nano-hardness and highest elastic modulus values can be obtained for the $a-\mathrm{C}: \mathrm{H}$ films deposited at Ar concentration of 50\%.

Optical studies were carried out by spectroscopic ellipsometry (SE) over 600-1700 nm range. Figure 4 shows variation of refractive index with wavelength for the films deposited at different Ar concentrations. It can be found from figure 4 that the refractive index values depend on wavelength as well as Ar concentration. The refractive indexes have the same tendency for the $a-\mathrm{C}: \mathrm{H}$ films prepared at different Ar concentrations, they decreased with increasing wavelength from 600 to $1700 \mathrm{~nm}$, but they did not change when the wavelength was longer than $1200 \mathrm{~nm}$. The refractive index of film deposited at 50\% Ar concentration is between 1.940 and 1.824 over the range $600-1700 \mathrm{~nm}$, and it is from 1.880 to 1.767 for the films deposited at $17 \%$ Ar concentration, while, it is between 1.755 and 1.703 at $86 \% \mathrm{Ar}$ concentration. For certain wavelengths within 600-1700 nm,

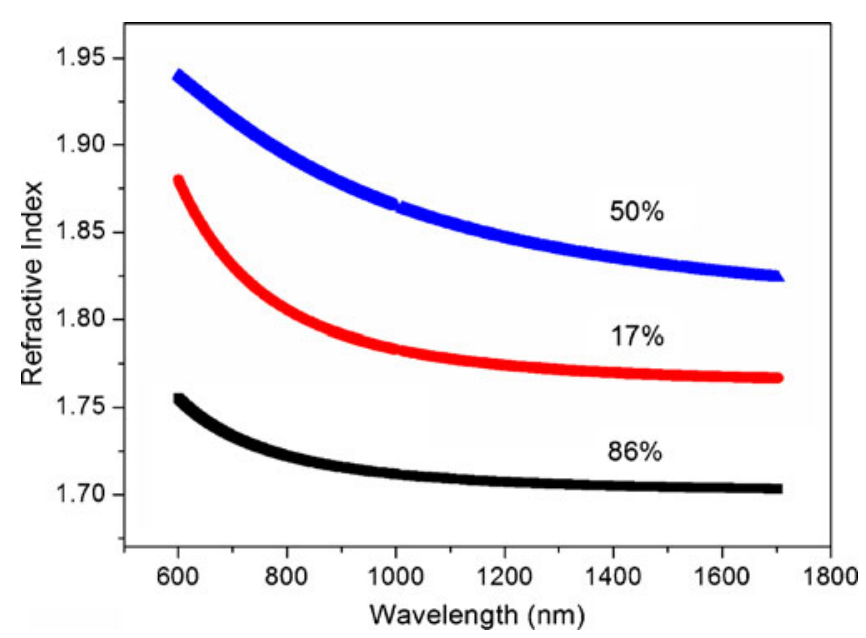

Figure 4. Variation of refractive index with wavelength for films deposited under different Ar concentrations. refractive index has the highest value at Ar concentration of $50 \%$, and it is smaller at the Ar concentration of $86 \%$ than at $17 \%$. According to the measured refractive index of the films deposited at different Ar concentrations, it can be deduced that film deposited at 50\% Ar concentration is dense in comparison with those deposited at $17 \%$ and $86 \%$ Ar concentration (Dey et al 2008; Singh et al 2008). Based on the above analyses, it is concluded that the $a-\mathrm{C}: \mathrm{H}$ films prepared by MFPUMST with a higher density have a higher refractive index, and also have more $s p^{3}$ fractions.

\section{Conclusions}

Amorphous hydrogenated carbon $(a-\mathrm{C}: \mathrm{H})$ films were synthesized by MFPUMST with a mixture of methane and argon as working gas. The effect of Ar concentration in the mixture gas on the bonds structure, mechanical properties and refractive index for such films was investigated.

(I) Raman and XPS spectra show that $s p^{3}$ fraction in the $a$ $\mathrm{C}: \mathrm{H}$ films increases with increasing Ar concentration from $17 \%$ to $50 \%$, while it decreases with increasing Ar concentration from $50 \%$ to $86 \%$. The effect of changes in $\mathrm{Ar}$ concentration on the $s p^{3}$ fraction can be explained by the sub-plantation model.

(II) Nano-indentation measurements show that the nanohardness and elastic modulus for the $a-\mathrm{C}: \mathrm{H}$ films increase with increasing Ar concentration from $17 \%$ to 50\%, while it decreases when Ar concentration is above $50 \%$.

(III) Spectroscopic ellipsometry measurements show that the refractive index for the deposited $a-\mathrm{C}: \mathrm{H}$ films at different $\mathrm{Ar}$ concentrations show the same tendency in the range of wavelength from $600 \mathrm{~nm}$ to $1700 \mathrm{~nm}$. And for certain wavelength within 600-1700 $\mathrm{nm}$, the refractive index has the highest value at a Ar concentration of $50 \%$, and it is smaller at a $\mathrm{Ar}$ concentration of $86 \%$ than at $17 \%$.

(IV) Based on the analyses shown here, the Ar concentration in the mixture of methane and argon gas plays an important role in the bonding structure, mechanical and optical properties of $a-\mathrm{C}: \mathrm{H}$ films deposited by middle frequency pulsed unbalanced magnetron sputtering technique. It is concluded that the $a-\mathrm{C}: \mathrm{H}$ films prepared by MFPUMST with a higher density have a higher refractive index, and also have more $s p^{3}$ fraction.

\section{References}

Buijnsters J G, Camero M and Vazquez L 2006 Phys. Rev. B74 155417

Chowdhury S, Laugier M T and Rahman I Z 2004 Thin Solid Films 468149

Clin M, Durand-Drouhin O, Zeinert A and Picot J C 1999 Dia. Relat. Mater. 8527

Dai H Y, Wang L W, Jiang H and Huang N K 2007 Chin. Phys. Lett. 242122 
Dai H Y, Jiang H, Zhan C Y and Huang N K 2009 Surf. Interf. Anal. 41560

Dey R M et al 2008 Curr. Appl. Phys. 86

Huang Z H, Yang B, Fan X J and Fu D J 2006 Nucl. Sci. Technol. 17135

Kumari K, Banerjee S, Chini T K and Ray N R 2009 Bull. Mater. Sci. 32563

Lifshitz Y 1996 Dia. Relat. Mater. 5388

Liu Y H, Li J, Liu D P and Ma T C 2006 Surf. Coat. Technol. 200 5819
Myung H S, Park Y S, Lee J W, Hong B and Han J G 2005 Thin Solid Films 475303

Peng X L, Barber Z H and Clyne T W 2001 Surf. Coat. Technol. 13823

Robertson J 2002 Mater. Sci. Eng. R37 129

Singh S B et al 2008 Bull. Mater. Sci. 31813

Wang K, Liang H, Martin J M and Mogne T L 2007 Appl. Phys. Lett. 91051918

Zou Y S, Wang W, Song G H, Du H, Gong J, Huang R F and Wen L S 2004 Mater. Lett. 583271 